\title{
High infection to SARS-CoV-2 in an indigen community of the Colombian Amazon
} region.

Hector Serrano-Coll ${ }^{1,2}$, Hollman Miller ${ }^{3}$, Camila Rodríguez-Van der hamen ${ }^{4}$, Bertha Gastelbondo $^{1}$, Wilkhen Novoa $^{5}$, Misael Oviedo ${ }^{6}$, Ricardo Rivero ${ }^{1}$, Evelyn Garay ${ }^{1}$, Salim $\operatorname{Mattar}^{1 *}$

1. Universidad de Córdoba, Instituto de Investigaciones Biológicas del Trópico, Montería, Colombia.

2. Instituto Colombiano de Medicina Tropical-Universidad CES, Medellín Colombia.

3. Secretaria de Salud del Vaupés, Mitú.

4. Organización SINERGIAS alianzas para la vida, Bogotá, Colombia.

5. Fundación GAIA Amazonas,6. Corporación Colombiana de Investigación Agropecuaria Agrosavia, Centro de investigación Turipaná, Cereté, Córdoba - Colombia.

Introduction. COVID-19 is a pathology caused by the SARS-CoV2 virus. The World Health Organization has reported more than 225 million cases and 4.5 million deaths worldwide. Objective: To describe the seroprevalence, spatial distribution, and clinical and sociodemographic variables of SARS-CoV2 in a community of the Colombian Amazon region. Methods. In December 2020, a cross-sectional observational study was carried out in a population located in the Colombian Amazon in the municipality of Mitú. Sociodemographic and clinical data were taken. Besides, 590 blood samples were taken, and an antibody detection was carried out with an ELISA and a recombinant protein $\mathrm{N}$ antigen of SARS-CoV2. Results. A seroprevalence of 57.6\% was observed. The highest proportion of the infection is located in inter-municipal transport zones. The bivariate analysis did not show differences in the SARS-CoV2 infection rate concerning the variables sex, age-range, and the presence of comorbidities $(\mathrm{P}>0.05)$. The bivariate and multivariate analysis showed that being symptomatic and presenting neurological manifestations of the upper respiratory tract are clinical variables associated with SARS-CoV2 infection $(\mathrm{P}<0.05)$. One of the causes of this virus's high spread in this community could be that $53.3 \%$ of the people were asymptomatic. Conclusions. Our data showed a high burden and transmission of SARS- 
CoV-2 in this indigenous community. This could be linked to cultural behaviors and the high infection rate in asymptomatic patients.

Palabras clave: Public health, Population groups, Informal sector, asymptomatic diseases, Seroepidemiologic studies.

\section{Introduction}

The World Health Organization (WHO) has reported more than 225 million cases and 4.5 million deaths related to COVID-19 in the world (1). At present, in a short time, the clinical characteristics and environmental factors related to the spread of SARS-CoV-2 in the general population have been studied in depth (2). However, little is known about this infection in populations of indigenous descent.

Colombia is one of the largest populations with indigenous heritage, and some of them are found in the Amazon. More than 64 indigenous ethnic groups have been described, and 58\% of the inhabitants of this region belong to or have a genetic ancestry related to one of these ancestral communities $(3,4)$. On the other hand, these populations have certain cultural conceptions against this new virus, which would be linked to the little use of protection measures. Therefore, there would be a high proportion of asymptomatic individuals that would facilitate the spread of SARS-CoV-2. However, it is unknown in Colombia and neighboring countries such as Brazil, Peru, and Venezuela the behavior and spread of this virus in indigenous communities.

This work's objective was to describe the seroprevalence, spatial distribution, and clinical and sociodemographic variables related to SARS-CoV2 infection in a population of indigenous ancestry from the municipality of Mitú, Vaupés, Colombian Amazon.

\section{Methods.}

Type of study, geographic location, and size of the sample. In December 2020, a crosssectional observational study was carried out. The study was carried out in the municipality of Mitú, department of Vaupés, a region that occupies part of the great Colombian Amazon (5). The department is located in the South East of Colombia on the border with Brazil (Figure 1). Five hundred ninety people were included, the size of the sample was calculated 
based on the Mitú population of 16,580, with a reliability of $95 \%$ and a margin of error of 4\% (EPIDAT 3.1).

Ethical aspects. The research was carried out following the international ethical standards given by the WHO and the Pan American Health Organization, supported by the Declaration of Helsinki, and national legislation, resolution number 008430 of 1993 of the Ministry of Health of Colombia that regulates the studies in health. Furthermore, this work was endorsed by the ethics committee of the Tropic Biological Research Institute.

Serology. A blood sample was taken from each person to detect antibodies against SARSCoV-2. A commercial ELISA (Eurofins-Ingenasa. Madrid) was used, which uses a recombinant $\mathrm{N}$ protein for SARS-CoV2. The test measures totaled $\operatorname{IgG}, \operatorname{IgM}$, and $\operatorname{IgA}$ antibodies and were previously validated in our laboratory (6).

Analysis of data. Each individual was asked sociodemographic and clinical aspects, only one person was chosen for each household, and it was not taken into account whether they had suffered from the SARS-CoV-2 disease. For the registry of sociodemographic and clinical characteristics, an epidemiological survey was used by the Biological Research Institute of the Tropics. Data were analyzed using the Statistical Package for the Social Sciences version 21 (SPSS). The univariate analysis for the qualitative variables was carried out through the calculation of absolute and relative frequencies. The measures of central tendency were calculated as quantitative variables.

Further, the normality of the quantitative variables was determined by applying the Kolmogórov-Smirnov test. The bivariate analysis of the qualitative variables was carried out through Pearson's chi-square test. The qualitative \& quantitative variables analysis was done through the Mann-Whitney or Kruskal-Wallis U test in case the qualitative variable was polytomous. Multivariate analysis was performed through binomial logistic analysis. The significance of the P-value was established at $<0.05$. The analysis of the risk was made by calculating the Odds Ratio (OR), a confidence interval (CI) was included. Also, a map of points was made for the geolocation of the serological data using the QGIS software of the geographic information system version 3.4.15.

\section{Results.}


Sociodemographic and clinical characteristics. Of 590 people, a seroprevalence of $57.6 \%$ was obtained (Table 1). $56.9 \%$ were female gender and $43.1 \%$ male. $48.1 \%$ were in the age range between $20-39$ years. $16.8 \%$ had comorbidities, mainly arterial hypertension (27.3\%) and diabetes mellitus (17.2\%). $27.3 \%$ of people presented in the last three months pulmonary or extrapulmonary clinical manifestations associated with COVID-19. Of these people with previous symptoms, it was confirmed that $21.7 \%$ had one or more sick relatives with SARSCoV-2 (Table 1).

Table 1. Description of the sociodemographic and clinical characteristics of the study participants.

\begin{tabular}{ll}
\hline Characteristic of the individuals & $\mathrm{N}=590(\%)$ \\
\hline Sex & \\
Female & $336(56.9)$ \\
Male & $254(43.1)$ \\
\hline Age range (years) & $8(1.4)$ \\
$5-14$ & $50(8.5)$ \\
$15-19$ & $153(25.9)$ \\
$20-29$ & $131(22.2)$ \\
$30-39$ & $63(10.7)$ \\
$40-49$ & $69(11.7)$ \\
$50-59$ & $61(10.3)$ \\
$60-69$ & $31(5.3)$ \\
$\geq 70$ & \\
\hline Comorbidities & $99(16.8)$ \\
Yes & $27(27.3)$ \\
\hline Comorbidities related & $17(17.2)$ \\
Arterial hypertension & $6(6.1)$ \\
Diabetes mellitus (DM) & $49(49.4)$ \\
Arterial hypertension + DM & $161(27.3)$ \\
\hline Others & $340(57.6)$ \\
\hline Some family member diagnostic with COVID-19 \\
Yes & $128.7)$ \\
\hline Symptomatology related to COVID-19 \\
Yes & \\
\hline Seropositivity in Mitú & \\
\hline & \\
\hline & \\
\hline
\end{tabular}


Spatial distribution of SARS-CoV2 in the municipality of Mitú. Analysis of the point map showed a distribution of cases throughout the municipality. However, the cases were mainly concentrated in areas close to the airport terminal (Figure 1).

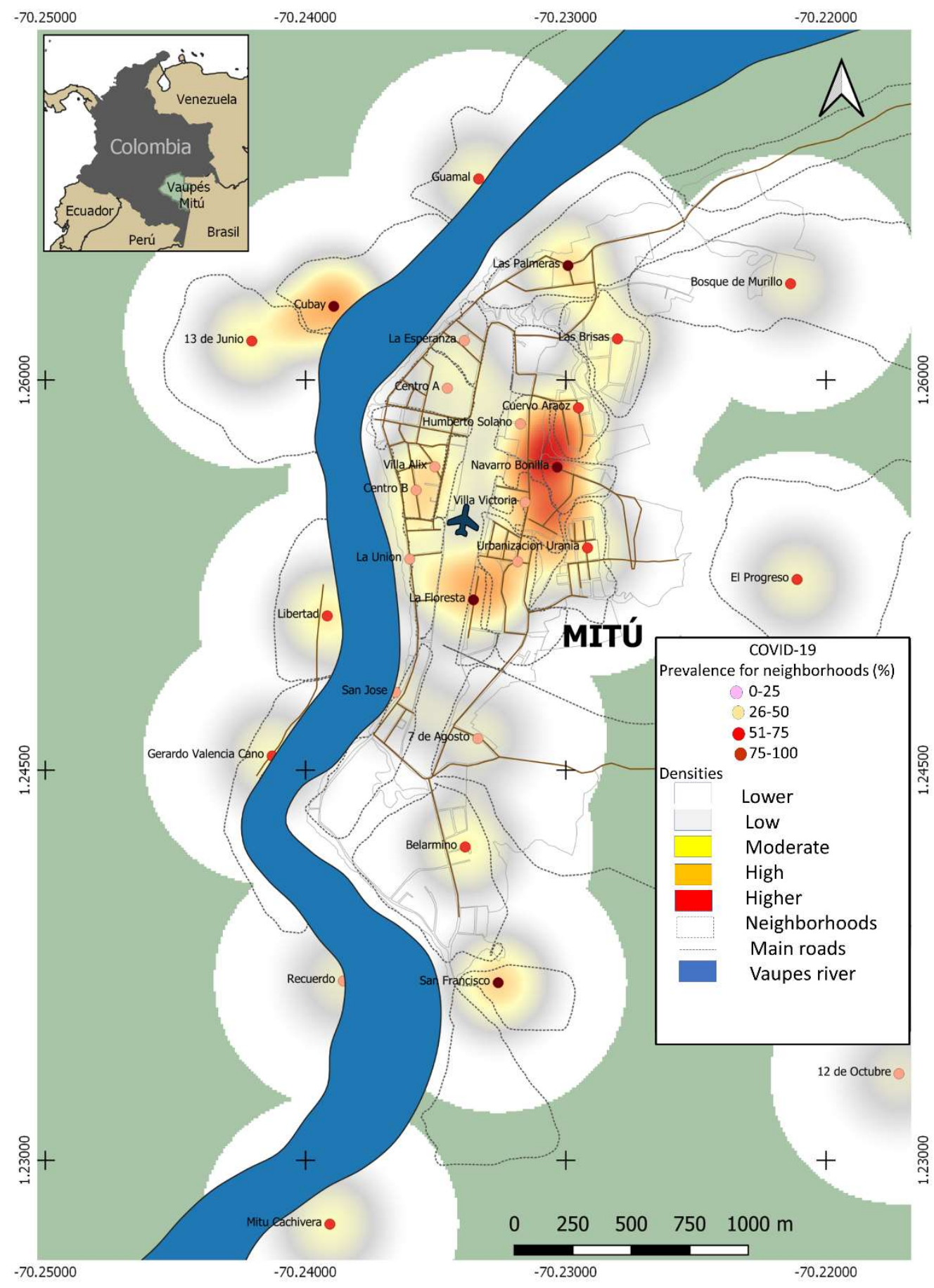


Figure 1. Spatial distribution through point map for SARS-CoV-2 infection in Mitú. A distribution of SARS-CoV2 cases is observed throughout the municipality of Mitú, with relevant areas of concentration of those infected by SARS-CoV2 close to airport terminal.

Seropositivity for SARS-CoV2 and gender. No statistically significant differences were found between the percentage of infection between men and women ( $\mathrm{P}>0.05)$ (Table 2, Figure 2). However, a high proportion of infected was evidenced in both genders ( $>55 \%)$.

Table 2. Relationship between seropositivity against SARS-CoV2 versus sex and age ranges in years.

\begin{tabular}{|c|c|c|c|}
\hline Variable & $\begin{array}{l}\text { Serology } \\
\text { CoV2 }\end{array}$ & gainst SARS- & \multirow{2}{*}{ P-value } \\
\hline Sex & $\begin{array}{l}\text { Positive } \\
(\%)\end{array}$ & Negative (\%) & \\
\hline Female & $197(59)$ & $137(41)$ & \multirow{3}{*}{0.74} \\
\hline Male & $142(55.9)$ & $112(44.1)$ & \\
\hline No data & $1(50)$ & $1(50)$ & \\
\hline $\begin{array}{l}\text { Age range } \\
\text { (years) }\end{array}$ & $\begin{array}{l}\text { Positive } \\
(\%)\end{array}$ & Negative (\%) & P-value \\
\hline $0-4$ & 0 & 0 & \multirow{11}{*}{0.58} \\
\hline $5-9$ & $1(100)$ & 0 & \\
\hline $10-14$ & $4(57.1)$ & $3(42.9)$ & \\
\hline $15-19$ & $34(68)$ & $16(32)$ & \\
\hline $20-29$ & $91(59.5)$ & $62(40.5)$ & \\
\hline $30-39$ & $78(59.5)$ & $53(40.5)$ & \\
\hline $40-49$ & $34(54)$ & $29(46)$ & \\
\hline $50-59$ & $35(50.7)$ & $34(49.3)$ & \\
\hline $60-69$ & $32(52.5)$ & $29(47.5)$ & \\
\hline$\geq 70$ & $15(48.4)$ & $16(51.6)$ & \\
\hline No data & $16(66.7)$ & $8(33.3)$ & \\
\hline
\end{tabular}




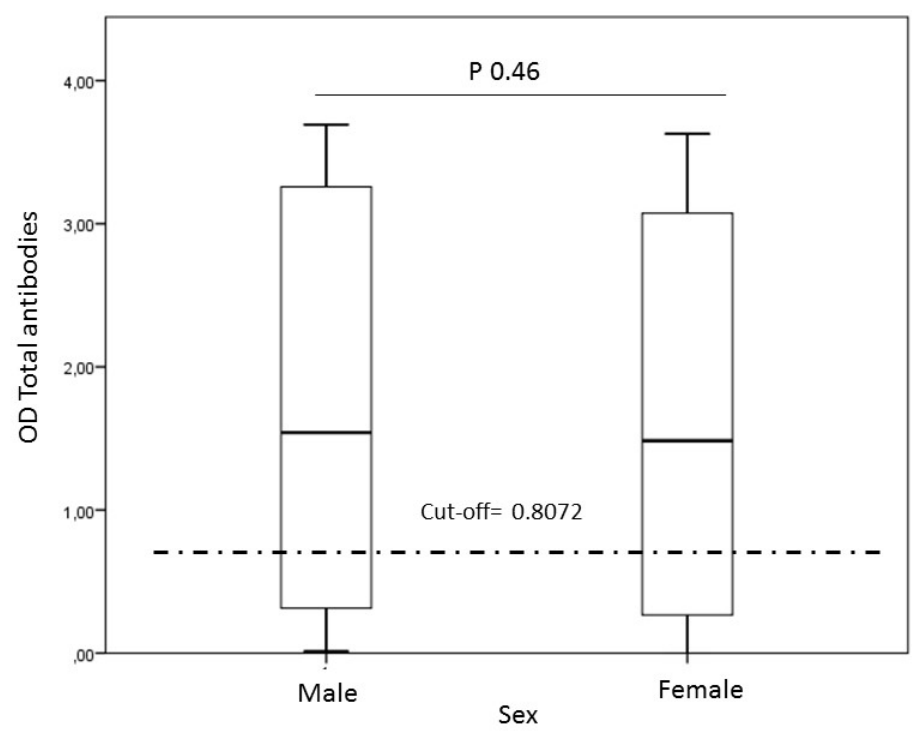

Figure 2. Relationship between sex versus serological data for SARS-CoV-2. A box made up of the 25 th, 50 th percentiles (median) is observed. 75 th and extreme values represent outliers. There is no difference in seropositivity or OD of total antibodies against SARSCoV2 between men and women. More than $50 \%$ of the data is well above the cut-off.

Relationship between seropositivity and age ranges. There were no differences between the percentage of SARS-CoV2 infection in the different age groups $(\mathrm{P}>0.05)$ (Table 2, Figure 3). Except for the group $\geq 70$ years, all the population groups presented seropositivity $>$ $50 \%$. 


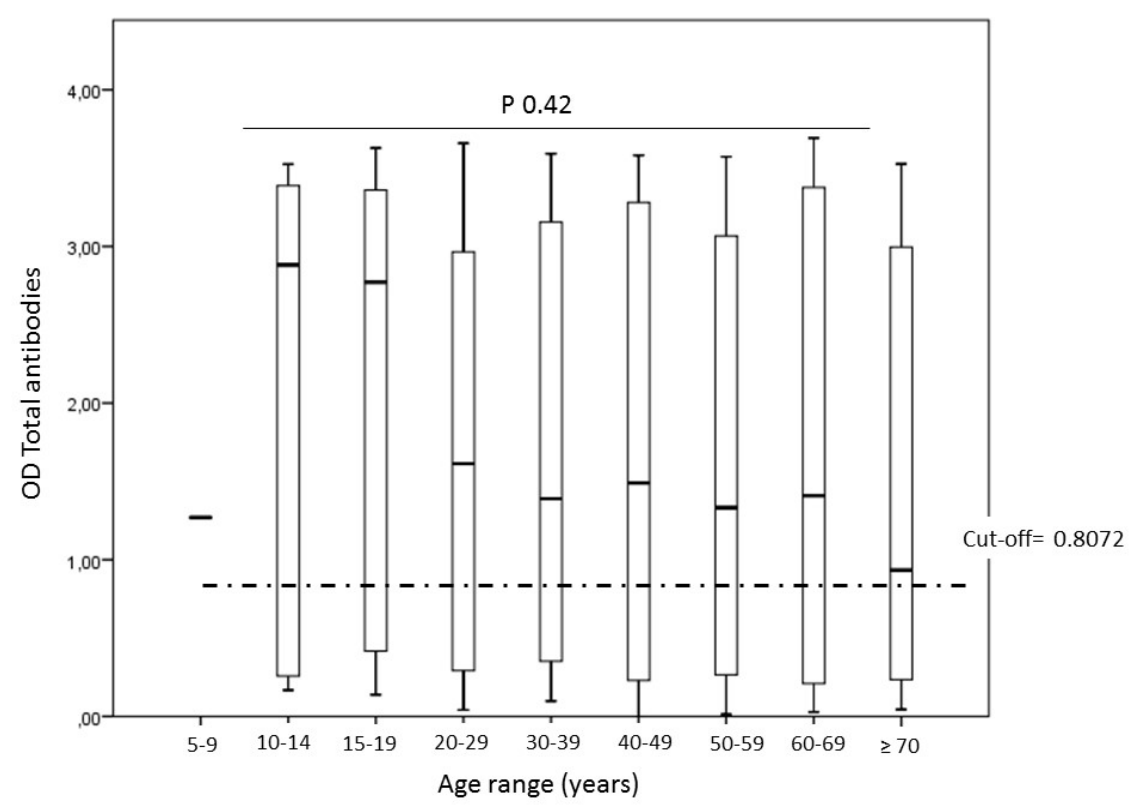

Figure 3. Relationship between the age ranges evaluated against the serological data for SARS-CoV-2. No statistically significant differences were observed when comparing the kinetics of total antibodies against the different age groups.

Seropositivity and comorbidities. Between individuals with some comorbidity and those who do not, no statistically significant differences were found with seroprevalence. However, $50 \%$ of the individuals with comorbidities had been exposed to this new coronavirus (Table 3 , Figure 4). 
Table 3. Seropositivity against SARS-CoV2 with comorbidities and symptoms of COVID-19

\begin{tabular}{|c|c|c|c|}
\hline \multirow{2}{*}{$\begin{array}{l}\text { Variables } \\
\text { Comorbidities }\end{array}$} & \multicolumn{2}{|c|}{$\begin{array}{l}\text { Serology against SARS- } \\
\text { CoV2 }\end{array}$} & \multirow{2}{*}{ P-value } \\
\hline & $\begin{array}{l}\text { Positive } \\
\text { (\%) }\end{array}$ & $\begin{array}{l}\text { Negative } \\
(\%)\end{array}$ & \\
\hline Yes & $51(51.5)$ & $48(48.5)$ & \multirow{3}{*}{0.39} \\
\hline No & $287(58.8)$ & $201(41.2)$ & \\
\hline No data & $2(66.7)$ & $1(33.3)$ & \\
\hline $\begin{array}{lll}\text { Symptoms } & \text { related } & \text { to } \\
\text { COVID-19 } & & \\
\end{array}$ & $\begin{array}{l}\text { Positive } \\
(\%)\end{array}$ & $\begin{array}{l}\text { Negative } \\
(\%)\end{array}$ & P-value \\
\hline Yes & $110(68.3)$ & $51(31.7)$ & \multirow{3}{*}{0.005} \\
\hline No & $219(53.3)$ & $192(46.7)$ & \\
\hline No data & $11(61.1)$ & 7 (38.9) & \\
\hline
\end{tabular}

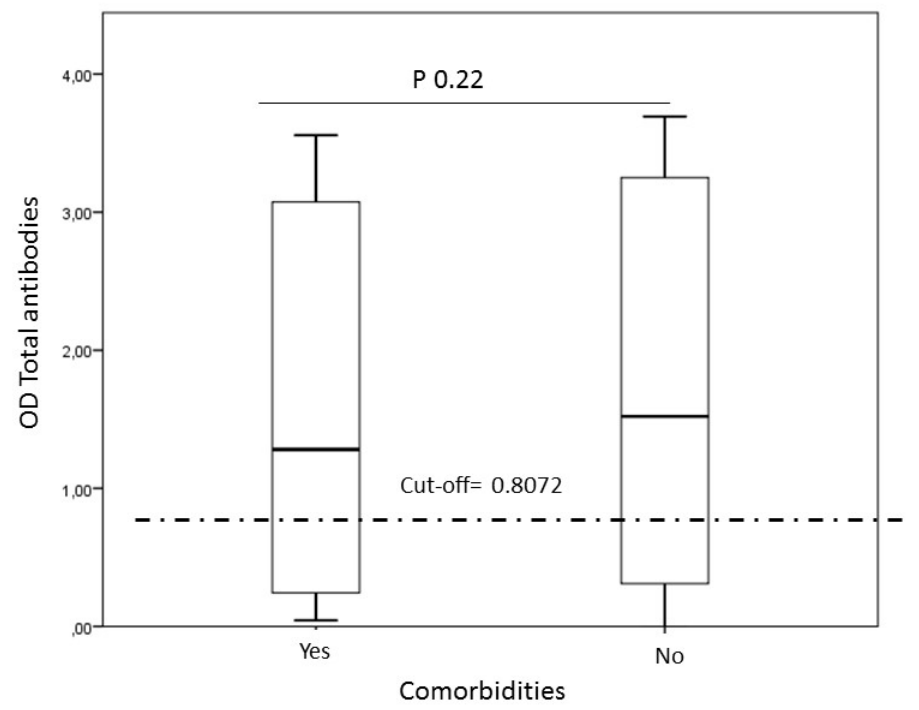


Figure 4 Relationship between having some comorbidity versus the serological data for SARS-CoV-2. No statistically significant differences were observed when comparing the total antibody kinetics between individuals with some comorbidity versus those who did not.

Seropositivity to SARS-CoV2 and history of clinical manifestations related to COVID19. Higher seroprevalence and elevated antibody titers against SARS-CoV2 were observed among individuals who had a history of pulmonary and extrapulmonary clinical manifestations in the last three months $\mathrm{P}<0.05$ ) (Table 3, Figure 5). 53.3\% of the asymptomatic individuals were seropositive.

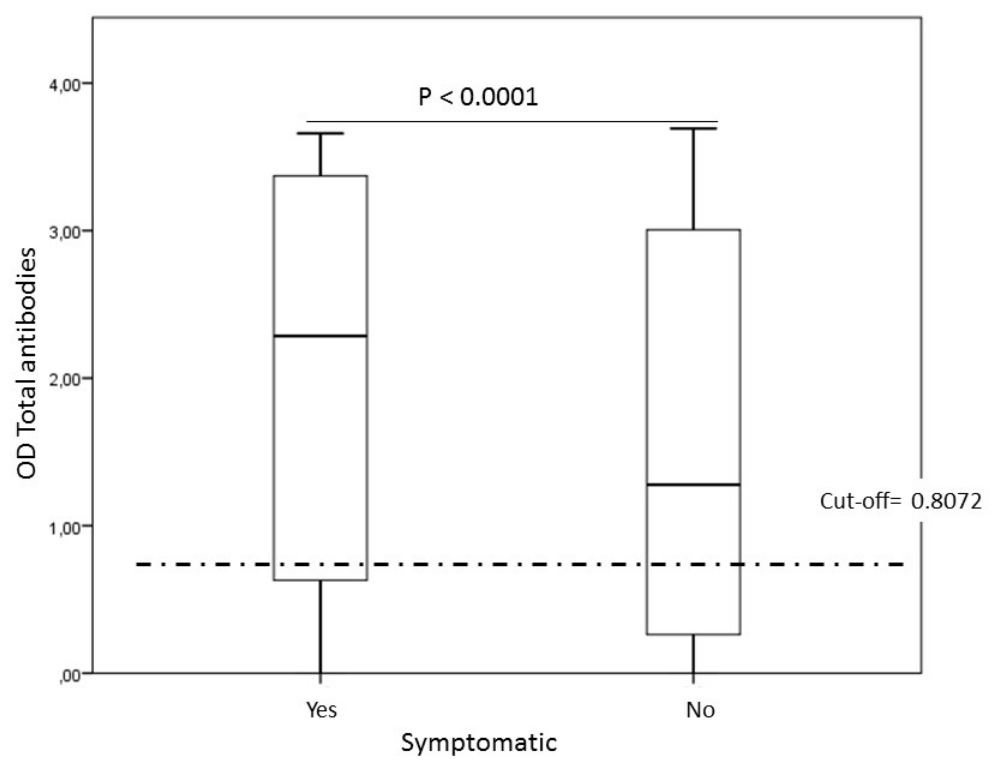

Figure 5. Relationship between the presence of clinical manifestations related to SARS$\mathrm{CoV}-2$ infection and the presence of a positive serological test for SARS-CoV-2. Higher seropositivity and OD of total antibodies are observed in individuals who had clinical manifestations related to SARS-CoV-2 infection.

Variables that explain the seropositivity for SARS-CoV2 in the municipality of Mitú.

The multivariate analysis through binomial logistic regression and the history of symptoms of this disease is the variable that best explains that an individual is seropositive against the virus $(\mathrm{P}<0.05)$. These individuals have a risk of being seropositive almost twice that of the rest of the general population [OR 1.9. 95\% CI 1.3-2.9] (Table 4). Considering that being symptomatic was an explanatory variable, it was decided to determine which of the clinical 
manifestations best explained seropositivity. The multivariate analysis showed that the upper respiratory tract's neurological disorders such as anosmia and ageusia are clinical manifestations that are related as a risk factor for this infection $(\mathrm{P}<0.05)$ [OR 2.3. 95\% CI 1.1-4.7]) (Table 5).

Table 4. Multivariate analysis among the cluster of variables evaluated with the probability of being seropositive for SARS-CoV2

\begin{tabular}{lll}
$\begin{array}{lll}\text { Multivariate } \\
\text { analysis }\end{array}$ & \multicolumn{2}{l}{ Seropositivity } \\
\cline { 2 - 3 } & P-value & OR 95\%CI \\
\hline Neighborhood & 0.8 & $\begin{array}{l}0.99 \\
1.02)\end{array}$ \\
\hline Sex & 0.45 & $1.1(0.8-1.6)$ \\
\hline Age range & 0.15 & $1.1(0.97-1.2)$ \\
\hline Symptoms & 0.002 & $1.9(1.3-2.9)$ \\
\hline Comorbidities & 0.27 & $0.75(0.5-1.2)$ \\
\hline
\end{tabular}

Table 5. Multivariate analysis among the cluster of clinical manifestations associated with COVID19 with the probability of being seropositive for SARS-CoV2

\begin{tabular}{llll}
\hline \multirow{2}{*}{$\begin{array}{l}\text { Multivariate } \\
\text { analysis }\end{array}$} & \multicolumn{3}{l}{ Seropositivity } \\
\cline { 2 - 4 } & P-value & OR 95\% CI \\
\hline Anosmia/ageusia & 0.028 & $2.3(1.1-4.7)$ \\
\hline Fever & 0.75 & $\begin{array}{l}0.96 \\
1.2)\end{array}$ & $(0.8-$ \\
\hline Dyspnea & 0.823 & $0.9(0.4-1.9)$ \\
\hline Headache & 0.1 & $\begin{array}{c}1.7 \\
3.3)\end{array}$ & $(0.88-$ \\
\hline Shortness breath & 0.68 & $\begin{array}{c}0.84 \\
1.6)\end{array}$ & $(0.4-$ \\
\hline Cough & 0.96 & $\begin{array}{l}0.98 \\
1.9)\end{array}$ & $(0.48-$ \\
\hline
\end{tabular}




\begin{tabular}{|c|c|c|}
\hline Diarrhea & 0.56 & $(0.58$ \\
\hline Nauseas/vomiting & 0.2 & $0.6(0.3-1.3)$ \\
\hline Myalgia & 0.7 & $0.9(0.4-1.8)$ \\
\hline
\end{tabular}

\section{Discussion.}

The seroprevalence against SARS-CoV2 evidenced in this area of the Colombian Amazon was $57.6 \%$ and could be considered within the seroprevalence studies as one of the world's highest. Our findings exceed those found in the principal city of the Brazilian Amazon, Manaus, where $44 \%$ community seroprevalence was reported (7), and the one made in Atahualpa Ecuador (8), with 45\%. At the local level, this infection rate is comparable to that observed by us in the city of Montería, where we show high community immunity against this new virus $(55 \%)(9)$.

The reasons that could explain this high seropositivity against SARS-CoV2 in the municipality of Mitu could be related to the typical cultural behaviors in these populations, such as sharing household utensils, having numerous family nuclei, and engaging in agricultural economic activities (10). Besides, Mitu is considered a small city of 16,580 inhabitants, and all these factors could influence the free circulation of SARS-CoV-2 and the high infection rate observed in this population. However, it is impossible to differentiate if these SARS-CoV-2 infections are active or an immunological trace of this infection since we evaluate total antibodies and not the active search for cases.

Regarding the spatial distribution of this infection, it was observed that the formal and informal trade zones and residential areas adjacent to inter-municipal transport zones were hotspots for SARS-CoV-2 infection in this population. These findings agree with Liu et al. ((11), in which it was observed that in these areas, the spread of SARS-CoV-2 is favored, mainly if biosafety measures such as social distancing, use of masks, and handwashing are not applied.

Regarding the sex of the population evaluated, no differences were found in the SARS-CoV2 infection rate. However, the high proportion of infected in both genders is striking, which is higher than 55\% and reflects an essential spread of this virus in men and women of Mitú. 
On the other hand, this finding makes us reconsider one of the paradigms of this disease: the greater susceptibility of SARS-CoV2 infection in males. Testosterone has been reported to promote androgen receptors at the nuclear level that facilitate the expression of TMPRSS2 receptors on the cell membrane, thereby promoting the entry of SARS-CoV2 into the host cell $(12,13)$. The male hormone can induce a greater expression of ACE2 receptors at the cardiac and renal level, which is another receptor involved in this infection's pathogenesis (12). Therefore, it would be necessary to analyze this topic more carefully. In the indigenous population and other populations, we did not find evidence that the SARS-CoV-2 infection rate is affected by the sex variable (14).

Regarding the evaluated age ranges, we did not find differences between the percentage of infection with SARS-CoV-2. This finding is consistent with what was found in Sergipe in Brazil, where no differences were found in the seropositivity rate concerning age ranges (15). However, the infection rate in these Brazilian age groups does not exceed $15 \%$. While in the present study the population of indigenous ancestry, the infection rate is higher than $48 \%$. It could be related to a higher infection rate in the ages $20-39$ years $(59.5 \%)$ because they are the predominantly productive age group. $60 \%$ of this population is engaged in informal economic activities (16), in which it is complicated to maintain self-care and isolation measures. Therefore, these infected individuals may have spread the virus to individuals of their family nuclei belonging to other age groups.

When comparing whether individuals with comorbidities presented greater seropositivity against SARS-CoV-2, it was not found that having hypertension or diabetes was related to an increase in the infection rate. However, it is essential to mention that suffering from comorbidities is related to greater severity and prevalence of complications such as acute respiratory distress syndrome, acute kidney injury, and septic shock (17).

The multivariate analysis showed that the presence of pulmonary and extrapulmonary symptoms of COVID-19 is the variable that best explains seropositivity against SARS-CoV2 in an indigenous population. Furthermore, it was found that the clinical manifestations of the upper respiratory tract such as anosmia and ageusia are clinical variables that can be pathognomonic of SARS-CoV-2 infection in this population, and these findings have also been reported in the general population (17). However, it is important to note that $53.3 \%$ of 
asymptomatic individuals had antibodies against SARS-CoV-2. This could be one of the principal explanations for the high seropositivity and widespread SARS-CoV-2 in this population. However, the present study's serological and clinical findings would be circumscribed mainly by the dynamics of the SARS-CoV-2 infection in the Mitú population. In other words, it is complex to extrapolate the data of this work with other indigenous communities of the Amazon, taking into account the ethnic plurality and genetics of these populations.

In conclusions, our data showed a high burden and transmission of SARS-CoV-2 in this indigenous community in 2020. Therefore, these findings show that is necessary to strengthen the sanitary services for future outbreaks that could be related to this coronavirus or other viruses. Finally, it is important to continue studying how this infection and other diseases compromise and impact the public health of these ancestry communities.

Acknowledgments. To GAIA Foundation, Rainforest Norway Foundation, NORAD, NICFI for the financial support. To Mitu municipal health secretary and its immediate response teams (ERI), community managers, health assistants, nurses, bacteriologists, anthropologists, and other departmental ERIs and DANE staff for their invaluable collaboration.

Authors' contributions. SM, HM, CR, WN designed the study. Participants in this study were evaluated by HM, WN, and CR The lab protocol was standardized (serology) and performed by RR, EG, BG. The data analysis was performed by HS. The manuscript was written by HS, SM, MO. The critical review was performed by CR, WN, HM, BG. This research was directed by SM. All authors read and approved the manuscript.

Ethical approbation. The research was carried out following the international ethical standards given by the WHO and the Pan American Health Organization, supported by the Declaration of Helsinki, and national legislation, resolution number 008430 of 1993 of the Ministry of Health of Colombia that regulates the studies in health. Furthermore, this work was endorsed by the ethics committee of the Tropic Biological Research Institute.

Consent for publication. Not applicable. 
Availability of data and materials. The raw data supporting the conclusions of this article will be made available by the authors, without undue reservation, to any qualified researcher.

Competing interests. The authors declare that they have no competing interests.

Funding. Any organization did not fund our project.

\section{References.}

1. World Health Organization. Coronavirus Disease (COVID-19) Dashboard [Internet]. 2021. Available from: https://covid19.who.int/

2. Meyerowitz EA, Richterman A, Gandhi RT, Sax PE. Transmission of SARS-CoV-2: A Review of Viral, Host, and Environmental Factors. Ann Intern Med. 2020 Sep 17;

3. Comisión Económica para América Latina y el Caribe (CEPAL). Amazonia posible y sostenible $\quad$ [Internet]. 2013. Available from: https://www.cepal.org/sites/default/files/news/files/folleto_amazonia_posible_y_sosteni ble.pdf

4. Organización Nacional Indígena de Colombia (ONIC). Emergency in the department of Amazonas, Colombia, due to the threat by the COVID-19 pandemic to Indigenous peoples [Internet]. 2020. Available from: https:/www.onic.org.co/en/internationalstatements/3855-emergency-in-the-department-of-amazonas-colombia-due-to-thethreat-by-the-covid-19-pandemic-to-indigenous-peoples

5. Departamento Administrativo Nacional de Estadística. Censo Nacional de Población y Vivienda - CNPV 2018 [Internet]. 2018. Available from: www.dane.gov.co > censo2018 > CNPV-2018-VIHOPE-v2

6. Eurofins. INgezim-COVID-19 DR [Internet]. 2020. Available from: https:/www.eurofins-technologies.com/ingezim-covid-19-dr.html

7. Buss LF, Prete CA, Abrahim CM, Mendrone A, Salomon T, de Almeida-Neto C, et al. COVID-19 herd immunity in the Brazilian Amazon. medRxiv. 2020 Jan $1 ; 2020.09 .16 .20194787$.

8. Del Brutto OH, Costa AF, Mera RM, Recalde BY, Bustos JA, García HH. SARS-CoV2 in rural Latin America. A population-based study in coastal Ecuador. Clin Infect Dis. 2020 Jul 27;

9. Mattar S, Alvis-Guzman N, Garay E, Rivero R, García A, Botero Y, et al. Severe Acute Respiratory Syndrome Coronavirus 2 Seroprevalence Among Adults in a Tropical City of the Caribbean Area, Colombia: Are We Much Closer to Herd Immunity Than Developed Countries? Open Forum Infect Dis. 2020 Dec;7(12):ofaa550. 
10. Cupertino GA, Cupertino M do C, Gomes AP, Braga LM, Siqueira-Batista R. COVID19 and Brazilian Indigenous Populations. Am J Trop Med Hyg. 2020 Aug;103(2):60912.

11. Liu T, Gong D, Xiao J, Hu J, He G, Rong Z, et al. Cluster infections play important roles in the rapid evolution of COVID-19 transmission: A systematic review. Int J Infect Dis. 2020 Oct;99:374-80.

12. Gebhard C, Regitz-Zagrosek V, Neuhauser HK, Morgan R, Klein SL. Impact of sex and gender on COVID-19 outcomes in Europe. Biol Sex Differ. 2020 May 25;11(1):29.

13. Hussain AN, Hussain F, Hashmi SK. Role of testosterone in COVID-19 patients - A double-edged sword? Med Hypotheses. 2020 Nov; 144:110287.

14. Garay E, Serrano-Coll H, Rivero R, Gastelbondo B, Faccini-Martínez Á, Berrocal J, et al. SARS-CoV-2 in eight municipalities of the Colombian tropics: high immunity, clinical and sociodemographic outcomes. Trans R Soc Trop Med Hyg. 2021 Jun 29; trab094.

15. Borges LP, Martins AF, de Melo MS, de Oliveira MGB, Neto JM de R, Dósea MB, et al. Seroprevalence of SARS-CoV-2 IgM and IgG antibodies in an asymptomatic population in Sergipe, Brazil. Rev Panam Salud Publica. 2020;44:e108.

16. Ministerio del Trabajo-Colombia. Fuente de información laboral en Colombia [Internet]. 2016 [cited 2021 Jan 15]. Available from: http://filco.mintrabajo.gov.co/FILCO/faces/estadisticas.jsf

17. Lechien JR, Chiesa-Estomba CM, De Siati DR, Horoi M, Le Bon SD, Rodriguez A, et al. Olfactory and gustatory dysfunctions as a clinical presentation of mild-to-moderate forms of the coronavirus disease (COVID-19): a multicenter European study. Eur Arch Otorhinolaryngol. 2020 Aug;277(8):2251-61. 